\title{
Review \\ Peculiarity of methoxy group-substituted phenylhydrazones in Fischer indole synthesis
}

\author{
By Yasuoki MuRAKAMI ${ }^{* 1, \dagger}$
}

(Communicated by Takao SEKIYA, M.J.A.)

\begin{abstract}
We found that the Fischer indole synthesis of ethyl pyruvate 2-methoxyphenylhydrazone (5) with $\mathrm{HCl} / \mathrm{EtOH}$ gave an abnormal product, ethyl 6-chloroindole-2-carboxylate (7), as the main product, with a smaller amount of ethyl 7-methoxyindole-2-carboxylate (6) as the normal product. This abnormal reaction was the result of a cyclization on the side with the substituent (methoxy group) of a benzene ring on phenylhydrazone, which was not previously observed. In this initial investigation, we focused on 1) the application of the above-mentioned abnormal Fischer indole synthesis, 2) the details of this reaction of phenylhydrazone with other kinds of substituents, 3) the mechanism of the first step of the Fischer indole synthesis, 4) the abnormal reaction in methoxydiphenylhydrazones, and 5) a synthetic device to avoid an abnormal reaction. The results of these studies are summarized herein.
\end{abstract}

Keywords: Fischer indole synthesis, methoxy group, abnormal reaction, phenylhydrazone, reaction mechanism, natural product

\section{Introduction}

Many natural products having an indole skeleton $^{1)}$ (1, Fig. 1), the compounds derived from them, and numerous purely synthetic indoles have been used as medicines. ${ }^{2}$ Thus, there are many methods for synthesizing an indole skeleton. Fischer indole synthesis $^{3)}$ (sometimes called Fischer indolization) is one of the oldest and most convenient, and it is currently used for a broad range of applications. Fischer indole synthesis (abbreviated as F.I.) is a method of obtaining indole compounds (4) simply by heating phenylhydrazones $(\mathbf{3})$ in the presence of an acid catalyst (Fig. 2). The detailed reaction mechanism was established only recently, though the basic mechanism was presumed upon the discovery of the reaction. There are some of our contributions in that, too.

We discovered the unique properties of the F.I. of 2-methoxyphenylhydrazones (generally speaking, methoxy-substituted phenylhydrazones) at an initial

*1 Professor, Faculty of Pharmacy, Chiba Institute of Science, Chiba, Japan.

$\dagger$ Correspondence should be addressed: Y. Murakami, Professor, Faculty of Pharmacy, Chiba Institute of Science, Shiomi-cho 15-8, Choshi, Chiba 288-0025, Japan (e-mail: ymurakami@cis.ac.jp). stage of the synthetic study of mitomycin $\mathrm{C}^{4)}(\mathbf{2})$ (Fig. 1) and the relevant compounds. In this report, we provide an overview of our work.

\section{Fischer indole synthesis of 2-methoxyphenylhydrazone (5)}

Many synthetic studies of mitomycin $\mathrm{C}$ and related compounds with an oxygen function at the 7 -position of the indole skeleton had been reported before we began the present work. However, these previous investigations did not employ F.I. Therefore, we examined F.I. of ethyl pyruvate 2-methoxyphenylhydrazone (5) to obtain a good starting material for the synthesis of $\mathbf{2}$. The compound expected from the F.I. of $\mathbf{5}$ was ethyl 7 -methoxyindole-2-carboxylate (6) (Fig. 3). In a previous work $^{5)}$ the compound (6) was prepared from 5 with $\mathrm{H}_{2} \mathrm{SO}_{4} / \mathrm{EtOH}$, whereas a compound of unknown structure was provided with $\mathrm{HCl} / \mathrm{EtOH}$, but a detailed study was not performed.

Therefore, we examined the reaction in detail and obtained the results shown in Fig. 3 and Table 1.6),7) In the reaction with $\mathrm{HCl} / \mathrm{EtOH}$ (Run 2), a compound (7) in which the chlorine was present instead of the methoxy group was obtained as the main product, but the yield of the expected compound (6) was poor. 


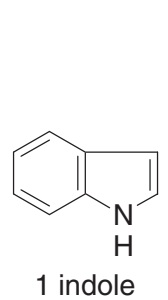<smiles>COC(=O)OC[C@]1(C)C2=C(C(=O)C(C)=C(N)C2=O)N2C[C@H]3C[C@H](N3)[C@@]21O</smiles><smiles>[R]CC([R])=NNc1ccc([X])cc1</smiles>

Fig. 2. Fischer indole synthesis.

Fig. 1.<smiles>CCOC(=O)C(C)=Cc1ccc2cc(C(=O)OCC)[nH]c2c1OC</smiles>

Fig. 3. F.I. of 2-methoxyphenylhydrazone (5) with saturated HCl/EtOH.

Table 1. F.I. of $\mathbf{5}$ with various acid catalysts

\begin{tabular}{|c|c|c|c|c|c|c|c|}
\hline \multirow{2}{*}{ Run } & \multirow{2}{*}{ Reagent } & \multicolumn{6}{|c|}{ Products $(\%)$} \\
\hline & & $7-\mathrm{OCH}_{3}(\mathbf{6})$ & $6-\mathrm{Cl}(\mathbf{7})$ & $6-\mathrm{OEt}(\mathbf{8})$ & $5-\mathrm{X}(\mathbf{9})$ & 3,4,5-Cl(mix.)(10) & $\mathrm{H}^{*}(\mathbf{1 1})$ \\
\hline 1 & $3 \mathrm{M} \mathrm{HCl} / \mathrm{EtOH}$ & 15.5 & 9.9 & 4.8 & 0 & 11.6 & 0 \\
\hline 2 & sat.HCl/EtOH & 4.2 & 34.7 & 0.26 & 0 & 7.7 & 0 \\
\hline 3 & $\mathrm{HCl} / \mathrm{AcOH}$ & 17.2 & 20.5 & - & 0 & 6.1 & 0 \\
\hline 4 & $\mathrm{H}_{2} \mathrm{SO}_{4} / \mathrm{EtOH}$ & 12.8 & - & 2.0 & 0 & - & 0 \\
\hline 5 & $\mathrm{ZnCl}_{2} / \mathrm{AcOH}$ & 17.7 & 0 & - & $1.3(\mathrm{X}=\mathrm{Cl})$ & 0 & 0 \\
\hline 6 & $\mathrm{BF}_{3} / \mathrm{AcOEt}$ & 15.0 & - & - & $4.7\left(\mathrm{X}=\mathrm{OCH}_{3}\right)$ & - & 2.7 \\
\hline
\end{tabular}

*:no substituent.

This was a completely unexpected result. We should note that an identical experimental result was reported ${ }^{8)}$ independently just before our report. However, we will explain the reaction based mainly on our findings, because our study was more detailed and was performed for a longer time.

To clarify the reaction mechanism, we examined the compounds resulting from this reaction using various kinds of acid catalysts. $\left.{ }^{6}\right), 7$ )

As a result, it was found that various abnormal products were formed along with the normal product (6). The key characteristics of the reaction are the following: 1) as shown in Runs 1 and 2, when the concentration of $\mathrm{HCl}$ decreases, the ratio of the $6-\mathrm{Cl}$ product (7) decreases, while formation of the 6-OEt compound (8) increases; 2) an indole having chlorine at a position other than 6 (compounds 10) is formed; 3) 5-substituted indoles (9) are formed in the case of the Lewis acid catalyst (Runs 5,6) by the substitution of chlorine (by $\mathrm{ZnCl}_{2}$ ) or migration of the methoxy group (by $\mathrm{BF}_{3}$ ); and 4) the total yield is lower (less than $45 \%$ ) in some reactions (other products were inseparable tarry ones). We will discuss the matter of the low yield of indoles later in this paper (see chapter 7).

First, we will consider the formation mechanism of the main product 7 . Because product (7) has a chlorine atom in place of the methoxy group, it must be concluded that the reaction occurred on the methoxy side rather than the vacant side to give the substitution product (7). Generally, it is apt to be thought that the cyclization and substitution do not advance at the position occupied by a substituent. However, Carlin ${ }^{9)}$ reported that the F.I. of a 2,6dimethylphenylhydrazone gave a 4,7-dimethylindole, accompanied with the migration of the substituent (Fig. 4). However, there has been no report on an F.I. in which phenylhydrazone with a substituent side and a vacant one in the two ortho-positions was cyclized on the substituent site.

Hereafter, we will refer to an F.I. that forms abnormal compounds as an abnormal F.I. Figure 5 shows the formation mechanism of the abnormal products forming $\mathbf{7}$, a center of the topic. This 


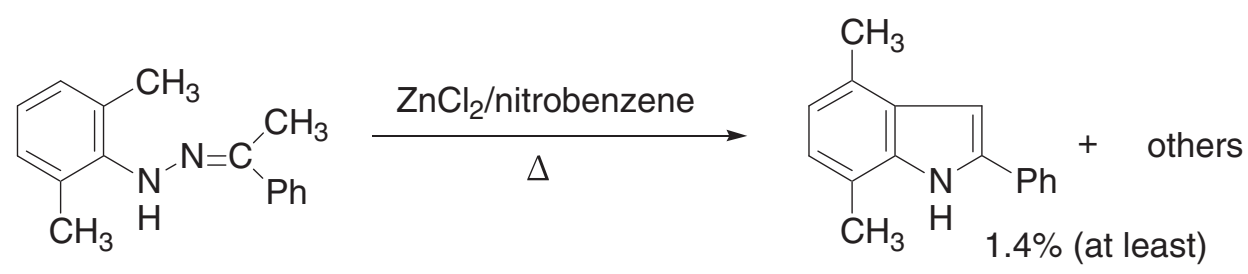

Fig. 4. Carlin's result.
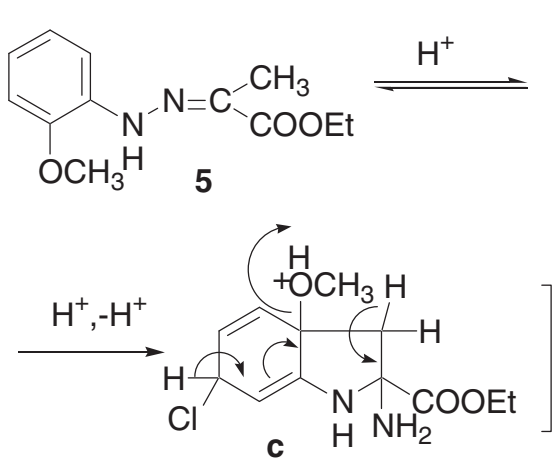

a

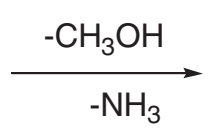

$7(8)$

Fig. 5. The mechanism of abnormal F.I. of $\mathbf{5}$.

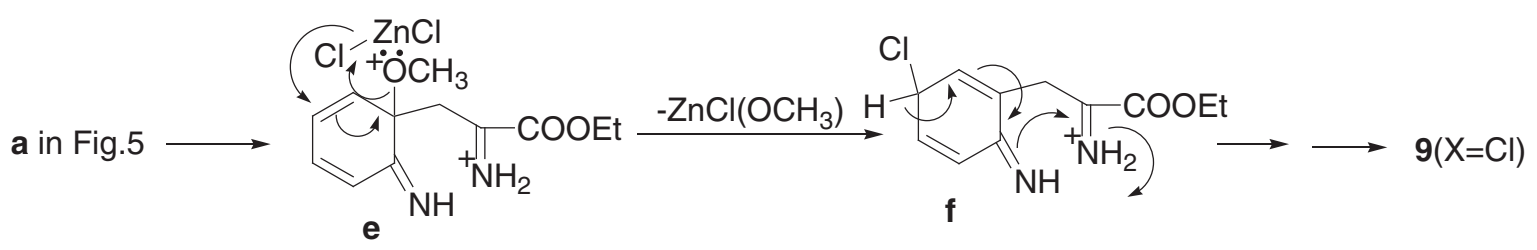

Fig. 6. The mechanism of the formation of 5-chloroindole (9).

mechanism is based on the established mechanism of the F.I. The mechanism of the conversion from 5 to $\mathbf{7}$ and $\mathbf{8}$ via intermediates $\mathbf{a}, \mathbf{b}$, and $\mathbf{c}$ in Fig. 5 explains well the formation of the 6 - $\mathrm{Cl}$ compound $(\mathbf{7})$ and 6 OEt compound (8). This reaction $(\mathbf{5} \rightarrow \mathbf{a} \rightarrow \mathbf{b} \rightarrow \mathbf{c} \rightarrow \mathbf{7})$ must be an $\mathrm{S}_{\mathrm{N}} 2$-type reaction, but in addition, there must be an $\mathrm{S}_{\mathrm{N}} 1$-type reaction that proceeds via the cation intermediate which is formed by the initial removal of the methoxy group prior to the introduction of a chloride ion, for a minor root (this latter $\mathrm{S}_{\mathrm{N}} 1$ mechanism is not described in our original paper). In the latter $\mathrm{S}_{\mathrm{N}} 1$ mechanism, cation rearrangement and the subsequent substitution may allow $\mathbf{1 0}$ to form, and an unknown reduction procedure may allow $\mathbf{1 1}$ to form.

The above-described mechanism is an example of a reaction using the proton acid catalyst, whereas the Lewis acid catalyst $^{7)}$ gave a different type of compound. When using the zinc chloride catalyst, on the other hand, substitution by the chlorine atom occurred at the 5 -position on the indole nucleus. This fact suggests that chlorine substitution may occur at the 5-position due to the zinc chloride coordinating more strongly with the methoxy group than with the proton acid (Fig. 6). We estimate the Lewis acidcatalyst reaction as follows: In the case of the boron trifluoride catalyst, substitution did not occur but rearrangement of the methoxy group did occur via an intermediate e (Fig. 6), resulting in the weak nucleophilicity of fluoride. In other words, it appeared that the difference in products resulted from the difference between the actions of proton acid and Lewis acid on the oxygen atom of the methoxy group.

Next, we performed the F.I. of 2,6-dimethoxyphenylhydrazone (12) to determine the behavior of 


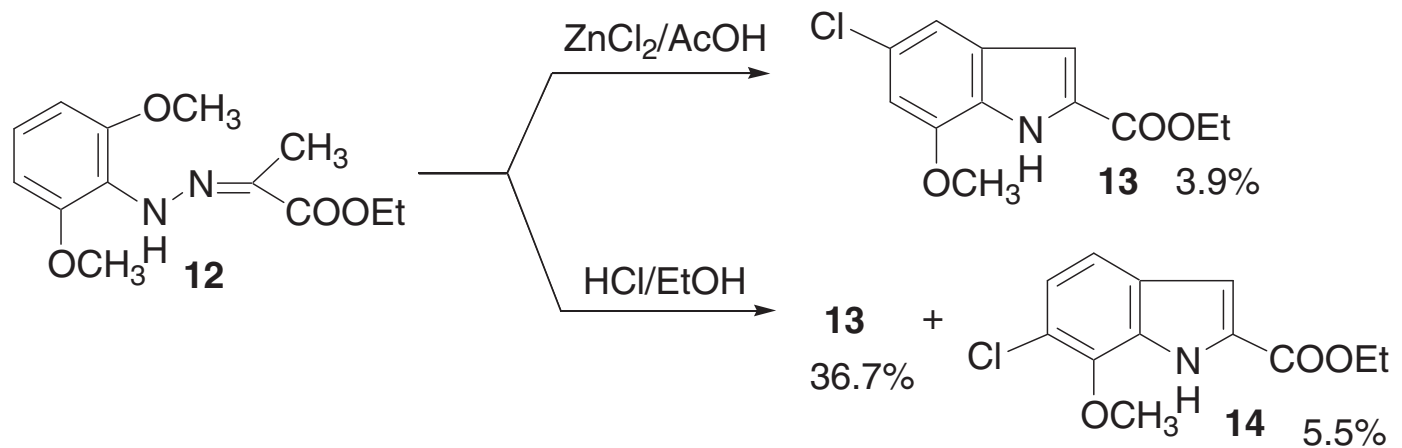

Fig. 7. The F.I. of 2,6-dimethoxyphenylhydrazone (12).
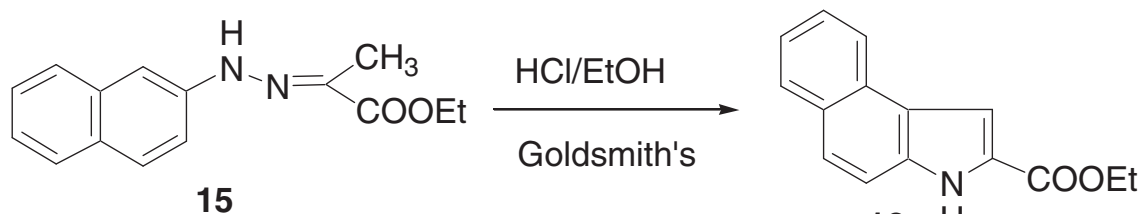

$16 \mathrm{H}$<smiles>CCOC(=O)C(C)=NNc1ccc2ccccc2c1OC</smiles>

17
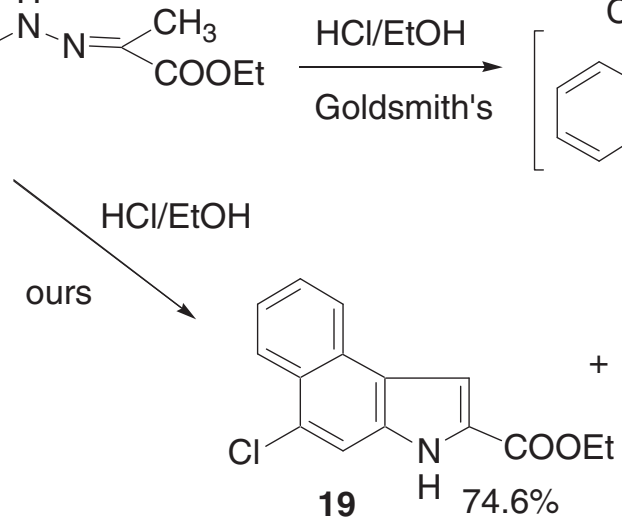<smiles>CCOC(=O)c1cc2cc3ccccc3c(OC)c2[nH]1</smiles>

18

Fig. 8. The F.I. of 1-methoxy-2-naphthylhydrazones.

the methoxy group in F.I. more clearly. ${ }^{7)}$ The result is shown in Fig. 7. The total yield of indole products in this case was lower than that in the case of 2methoxyphenylhydrazone $\mathbf{5}$. The main product in the case of the F.I. by $\mathrm{ZnCl}_{2} / \mathrm{AcOH}$ was 5-chloroindole (13), although the yield was as low as in the case of the phenylhydrazone (5). On the other hand, in F.I. by $\mathrm{HCl} / \mathrm{EtOH}$, the expected 6 -chloroindole (14) was formed in low yield, while $\mathbf{1 3}$ was the main product. The reason why it was difficult to substitute by $\mathrm{S}_{\mathrm{N}} 2$ for the chloride anion at the 6-position in this case is that the 7-methoxy group interfered with the approach of the chlorine. This is why the F.I. of $\mathbf{1 2}$ gave 5 -chloroindole $(\mathbf{1 3})$ as the main product by the $\mathrm{S}_{\mathrm{N}} 1$-type substitution, as seen in the reaction of the phenylhydrazone (5). It was clear that the F.I. of 2,6dimethoxyphenylhydrazone (12) took place in the root of the substituent, and this fact supported the validity of the reaction mechanism of 2-methoxyphenylhydrazone (5), which is described in Fig. 5.

\section{F.I. of naphthylhydrazone}

Goldsmith $^{10)}$ had reported that F.I. of 2-naphthylhydrazone (15) gave benz[e]indole (16) as a result of cyclization at the 1-position, but not at the 3-position (Fig. 8). This result is rational from the viewpoint of the reactivity of the naphthalene. We performed a supplementary examination that provided the same result, and the structure of the product was correct. However, Goldsmith reported ${ }^{10)}$ 
Table 2. Synthesis of 6-alkylindoles by abnormal F.I.

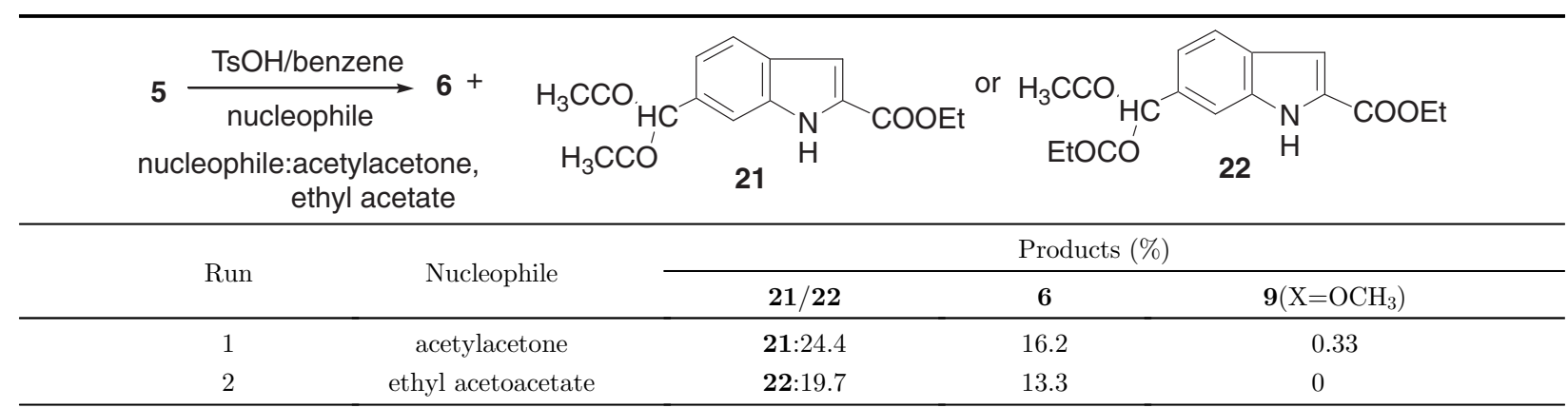

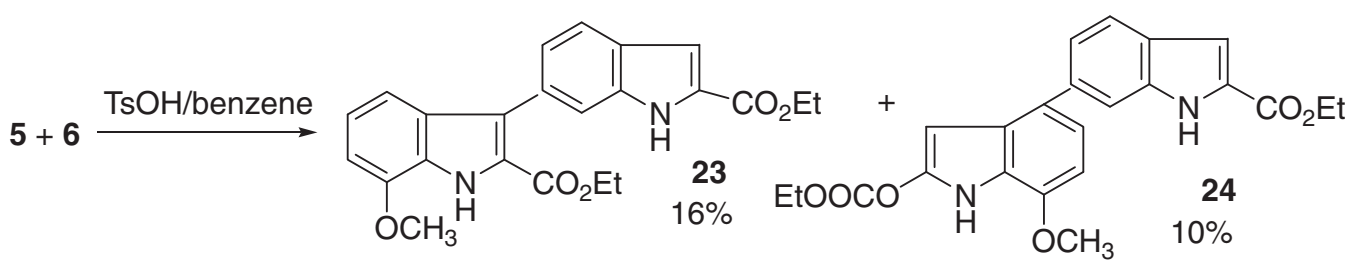

Fig. 9. Synthesis of indole dimers by abnormal F.I.

in the same paper that the F.I. reaction of $\mathbf{1 7}$ gave the benz $[f]$ indole $(\mathbf{1 8})$ as a result of cyclization at the 3 -position. Perhaps this was because they thought that the reaction was not caused at the 1-position due to the presence of the 1-methoxy group. In addition, this result is introduced in the review ${ }^{11)}$ as the only example of the synthesis of benz $[f]$ indole by F.I. However, we were skeptical in regard to the structure of 18 based on our results in Fig. 3 and Table 1. We therefore replicated their experiment in our supplementary examination, and obtained a material with the same melting point, but the structure was found $^{12)}$ to be $\mathbf{1 9}$, as we had expected. The minor product $\mathbf{2 0}$ was also another type of abnormal product. In addition, we found, as in the previous reports ${ }^{13), 14)}$ that our reaction advanced equally to the side of the 1-methoxy group with another 1methoxy-2-naphthylhydrazone. Therefore, our first result that F.I. proceeded to one of the orthopositions to which a methoxy group was substituted was proved to be universal.

\section{Syntheses of 6-alkyl- and 6-arylindole}

Among the abnormal indoles described above, we focused on the 6 -substituted indoles $(\mathbf{7}, \mathbf{8})$ formed from 2-methoxyphenylhydrazone (5). This is because their relative yields were considerably high, and also because it was hard to synthesize a 6 -substituted indole by another method at the time these results were reported. ${ }^{15)}$ Therefore we intended to apply the abnormal F.I. to intentional synthesis of 6-alkylsubstituted indoles. ${ }^{16)}$

In this experiment we used benzene as a solvent; $p$-toluenesulfonic acid ( $\mathrm{TsOH})$, which has strong acidity but low nucleophilicity, as a catalyst; and acetylacetone, ethyl acetoacetate, and diethyl malonate as nucleophiles. As a result, when acetylacetone and ethyl acetoacetate were used, the expected 6 -substituted indoles $(\mathbf{2 1}, \mathbf{2 2})$ were obtained. However, when diethyl malonate was used, the expected 6 -substituted products were not obtained at all. This was probably because diethyl malonate has low nucleophilicity in acidic media.

Next, when the same F.I. was performed using 7-methoxyindole (6) as a nucleophile, two kinds of the expected indolic dimer $(\mathbf{2 3}, \mathbf{2 4})$ were obtained (Fig. 9). The substitution position of the 7-methoxyindole (6) part in $\mathbf{2 3}$ is at the 3 -position, which is the most highly reactive position in the indole nucleus, and the substitution position at $\mathbf{2 4}$ is in the 4-position, which is activated by the methoxy group. At the time of these reports, the synthesis of biaryl compounds such as $\mathbf{2 3}$ and $\mathbf{2 4}$ was not easy, but these compounds can now be synthesized easily by the cross-coupling reaction ${ }^{17)}$ using $\mathrm{Pd}$ metal.

\section{Syntheses of naturally occurring 6-alkylindole}

As shown in Table 2 and Fig. 9, 6-alkylindoles could be easily synthesized by F.I. Syntheses of 6-substituted indoles, 6-(3-methylbuta-1,3-dienyl)in- 


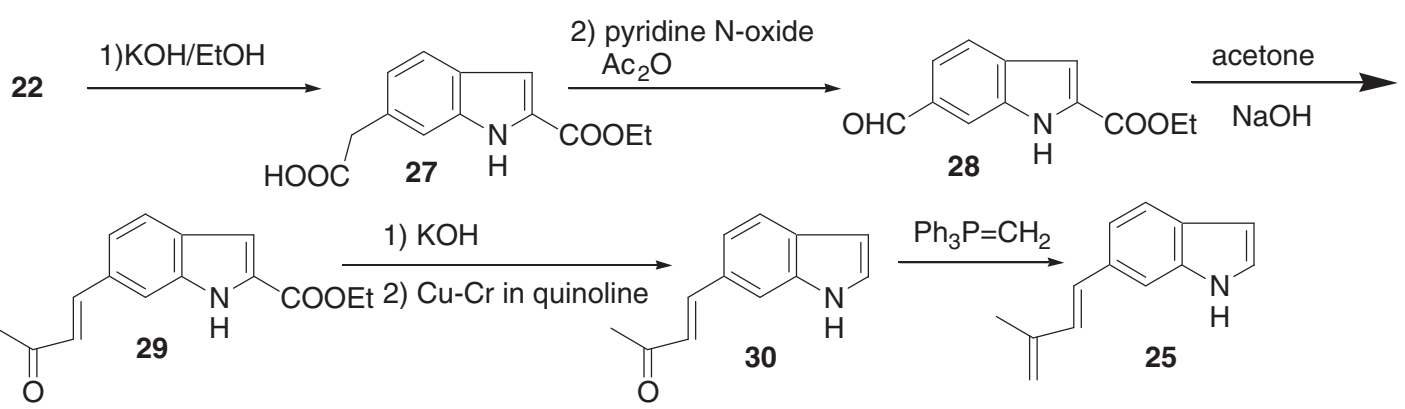

Fig. 10. Synthesis of 6-(3-methylbuta-1,3-dienyl)indole (25).
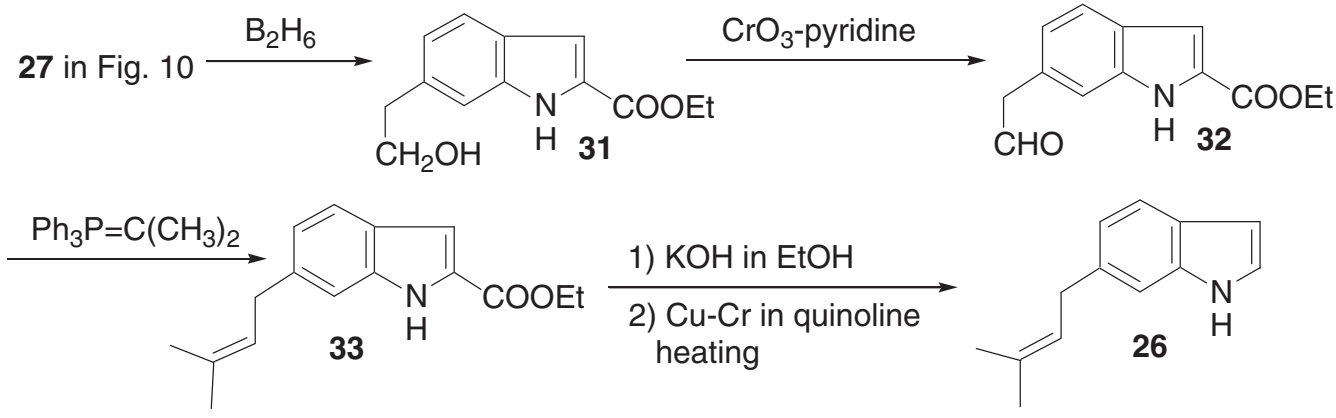

Fig. 11. Synthesis of 6-(3-methyl-2-butenyl)indole (26).<smiles>[R]C(C)=NNc1ccccc1</smiles>

34

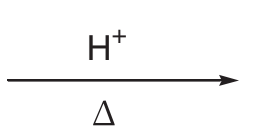

$\Delta$

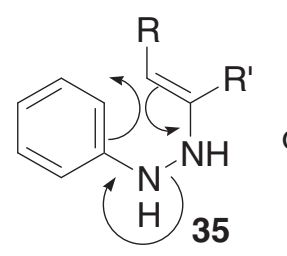

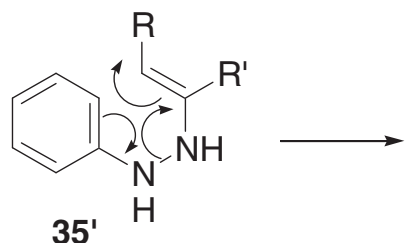

Fig. 12. The first step of F.I.

dole $(\mathbf{2 5})^{18)}$ and 6-(3-methyl-2-butenyl)indole $(\mathbf{2 6}),{ }^{19)}$ have been accomplished using this method. ${ }^{16), 20)}$ An outline of these reactions is shown in Figs. 10 and 11 .

As described in Fig. 10, the compound 22 shown in Table 2 was treated with $\mathrm{KOH} / \mathrm{EtOH}$, followed by treatment with pyridine $\mathrm{N}$-oxide/ $\mathrm{Ac}_{2} \mathrm{O}^{21}$ ) to give the aldehyde 28. Aldol condensation of $\mathbf{2 8}$ with acetone gave 29, whose ester group was removed by decarboxylation to give $\mathbf{3 0}$. Wittig reaction of $\mathbf{3 0}$ finally gave the natural product 25. Another natural product $\mathbf{2 6}$ was synthesized by a synthetic route similar to that used for $\mathbf{2 5}$ (Fig. 11).

\section{Proof for the first cyclization step of F.I. by a synthetic technique}

As for the mechanism (shown in Fig. 5) of the F.I., it was pointed out from the early stages of its discovery that the first cyclization step resembles the Claisen rearrangement reaction, which is known as a typical sigmatropy reaction. In addition, the complete reaction mechanism became clear afterwards, because various intermediates were caught up in various stages of the F.I. ${ }^{3)}$ However, it was the electron movement in the first cyclization step, which is shown as $\mathbf{3 5}$ or $\mathbf{3 5}$ ' in Fig. 12, that remained a problem until quite recently. The electron movement 35 was assumed on the basis of the nucleophilicity of the benzene nucleus, but $\mathbf{3 5}^{\prime}$ was assumed based on the high nucleophilicity of the enamine part. Electron movement 35 was more reasonable, but the experimental evidence for this movement was lacking.

Therefore we carried out the following experiments to confirm it by the synthetic method. As shown in Fig. 13, F.I. of asymmetric diphenylhydrazone 36 would give indolic products $\mathbf{3 7}$ and $\mathbf{3 8}$ in a 
<smiles>[X]c1ccccc1N(N=C(C)C(=O)OCC)c1ccccc1</smiles>

Fig. 13. The scheme for F.I. of diphenylhydrazones.

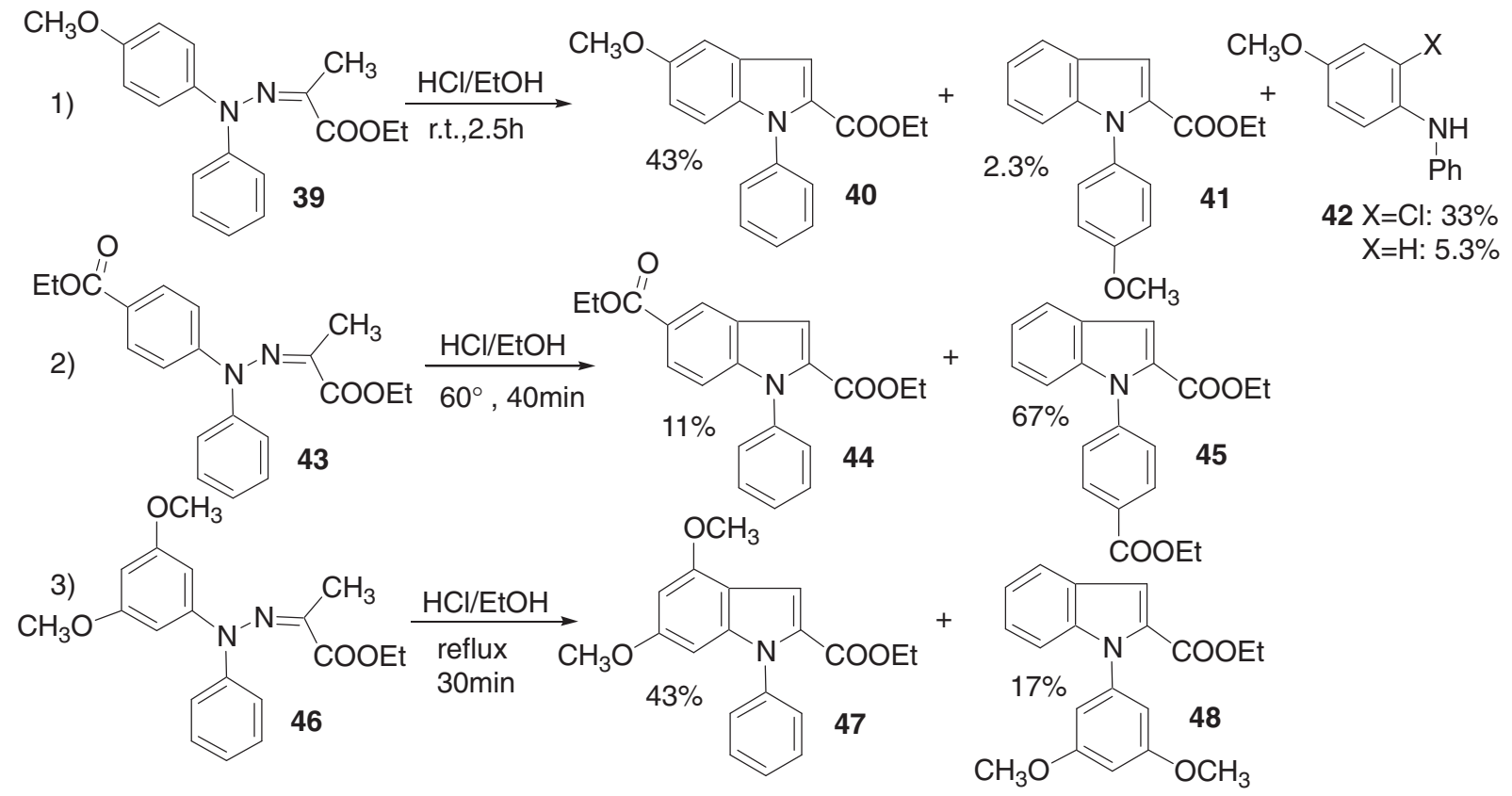

Fig. 14. The results of F.I. of diphenylhydrazones.

ratio depending on the electronic effect of substituent $\mathrm{X}$. The results of the experiment are shown in Fig. $14{ }^{22)}$

In the F.I. of diphenylhydrazone (39) having an electron donative methoxy group at the para position of one of the two benzene nuclei, the indole (40) formed in the cyclization toward the methoxysubstituted benzene was obtained in a larger excess amount than the product (41) formed by the cyclization at the other side. We will discuss the non-indolic product (42) later. On the other hand, the F.I. of diphenylhydrazone (43) having an electron-attractive ethoxycarbonyl at the para-position on one of the two benzene rings mainly occurred in the unsubstituted benzene. In addition, in the case of diphenylhydrazone (46) having two methoxy groups at meta-positions (3,5-dimethoxy), the cyclization to the substituted benzene ring had priority over the cyclization to the unsubstituted benzene. In this case, although there are two methoxy groups at the meta-position which activated the cyclization side, it is mysterious that the ratio of the yield of product (47) to the yield of (48) was small. However, a possible explanation for this result is that the F.I. of $m$-substituted phenylhydrazone gives ${ }^{23)}$ a larger amount of the $p$-cyclized indole than the $o$-cyclized one, because the $m$-substituent sterically hinders the cyclization. From these results, it was shown that F.I. proceeded readily toward the electron-rich benzene ring (generally an aromatic ring). Therefore, it was proved that the electronic movement of $\mathbf{3 5}$ in Fig. 12 had priority over that of $\mathbf{3 5}^{\prime}$.

Next, we carried out the F.I. of other diphenylhydrazone systems, as shown in Fig. 15, to examine the fate of the methoxy group in the orthomethoxyphenylhydrazones. ${ }^{24)}$

As in the case of the F.I. of $\mathbf{3 9}$ in Fig. 14, the formation rate of indoles was low in both orthomethoxyphenylhydrazones $(49 \mathrm{a}, \mathbf{b})$. In the case of dimethoxyphenylhydrazone (49a), the reaction pro- 


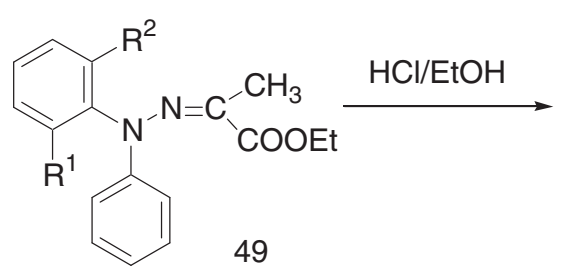<smiles>[X]c1ccc([R7])c2c1cc(C(=O)OCC)n2-c1ccccc1</smiles><smiles>[R]c1cccc([R])c1-n1c(C(=O)OCC)cc2ccccc21</smiles><smiles>CCOC(=O)/C(C)=N/N(c1ccccc1C)c1ccccc1OC</smiles>

$49 b-1$<smiles>CCOC(=O)/C(C)=N/N(c1ccccc1)c1ccccc1OC</smiles>

$49 b-2$<smiles>C=C(C(=O)OCC)N1COc2ccccc2N1c1ccccc1</smiles>

$49 b-3$

$$
\begin{array}{cc}
\text { Hydrazone } & \text { reaction condition } \\
49 \mathrm{a}: \mathrm{R}^{1}=\mathrm{R}^{2}=\mathrm{OCH}_{3} & \text { r.t. } / 30 \mathrm{~min} \\
49 \mathrm{~b}: \mathrm{R}^{1}=\mathrm{OCH}_{3}, \mathrm{R}^{2}=\mathrm{H} & \text { r.t. } / 40 \mathrm{~min}
\end{array}
$$$$
50
$$$$
12 \%\left(\mathrm{X}=6-\mathrm{Cl}, \mathrm{R}^{1}=7-\mathrm{OCH}_{3}\right) \quad 0 \%
$$$$
\left.4.1 \%(\mathrm{X}=6-\mathrm{Cl}, \mathrm{R} 1=\mathrm{H}) \quad 35 \%\left(\mathrm{R}^{1}=-\mathrm{OCH}_{3}, \mathrm{R} 2=\mathrm{H}\right)\right)
$$

Fig. 15. F.I. of 2-methoxy or 2,6-dimethoxydiphenylhydrazones (49).

ceeded in the direction of the electron-rich ring as in the case of NH-hydrazone (12) in Fig. 7. However, the F.I. of monomethoxyphenylhydrazone (49b) gave unexpected products. ${ }^{24)}$ In other words, the cyclization to an electron-deficient ring took first priority in the case of $\mathbf{4 9 b}$. This result was not expected based on the results of F.I. of the other ortho-methoxyphenylhydrazones $(\mathbf{5}, \mathbf{3 9}$, and $\mathbf{4 9 a})$. We interpreted it as follows: In view of the results, the conformation (49b-2) should have been given priority, although it had been thought that the conformations of phenylhydrazone that took part in the cyclization were $\mathbf{4 9 b}-\mathbf{1}$ and $\mathbf{4 9 b}-\mathbf{2}$. In this case we thought that $49 \mathrm{~b}-\mathbf{3}$, an enehydrazine tautomer of 49b-2, was stable by hydrogen bonding, and that is the reason why $49 \mathrm{~b}-\mathbf{2}$ was predominant.

In order to confirm the problem of the conformation fixed with the methoxy group in the enehydrazine structure shown in Fig. 15, the F.I. of 2,2'-dimethoxydiphenylhydrazone (52) (Fig. 16) was conducted.

As a result (Fig. 16), there were only a few indolic products, of which only $\mathbf{5 3}$ was obtained in a non-negligible quantity (4\%). On the other hand, the non-indolic by-product (described in Table 3) was obtained in $30 \%$ yield, and the significance of this result will be explained later. The indole (53) should have been provided by the cyclization at the vacant ortho-position of $\mathbf{5 2}$ in the conformation $\mathbf{5 5 a}$ but not $\mathbf{5 5 b}$. It is thought that this conformation (55a) was more unstable than $\mathbf{5 5 b}$ according to the steric hindrance of the methoxy group. This reaction did not generate the chloroindole $(\mathbf{5 4})$ at all, although $\mathbf{5 4}$ should have been permitted by the cyclization at the methoxy side in the conformation (55b). This result was not expected based on our previous result, and thus this fact shows the difficulty of presuming the conformation at the cyclization. In some cases, the F.I. was found to proceed with difficulty due to the simultaneous presence of a substituent in the $\mathrm{N}^{1}$ (the nitrogen connected directly with the benzene ring) and the ortho-position of the phenylhydrazone as in this experiment, as shown in the following example (Fig. 17) reported in our previous study. ${ }^{25)}$

Thus, the F.I. of the 2,6-dichloro- $N$ H-hydrazone (56) reacted smoothly and gave 5,7-dichloroindole (57) at a high yield. ${ }^{7}$ ) On the other hand, the F.I. of the corresponding $\mathrm{NCH}_{3}$ hydrazone (58) did not proceed readily and gave only a curious compound formed by the rearrangement of the methyl group at the 1 -position to the 3 -position in very low yield with high recovery of the starting material. ${ }^{25)}$ This result was probably also due to the fact that the phenylhydrazone (58) cannot be converted to the suitable conformation necessary for the F.I. cyclization by the presence of the substituent at $\mathrm{N}^{1}$ (the 1-position). 


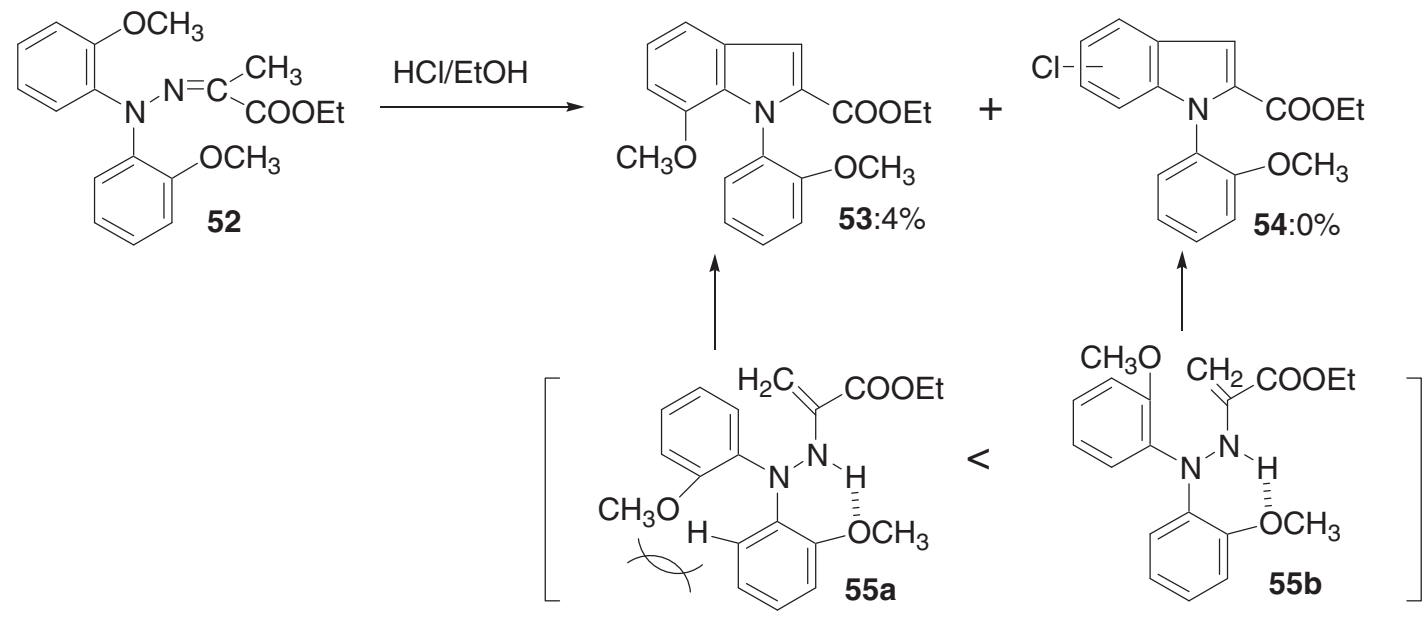

Fig. 16. F.I. of 2,2'-dimethoxydiphenylhydrazone (52).

Table 3. Abnormal formation of chlorinated diphenylamines

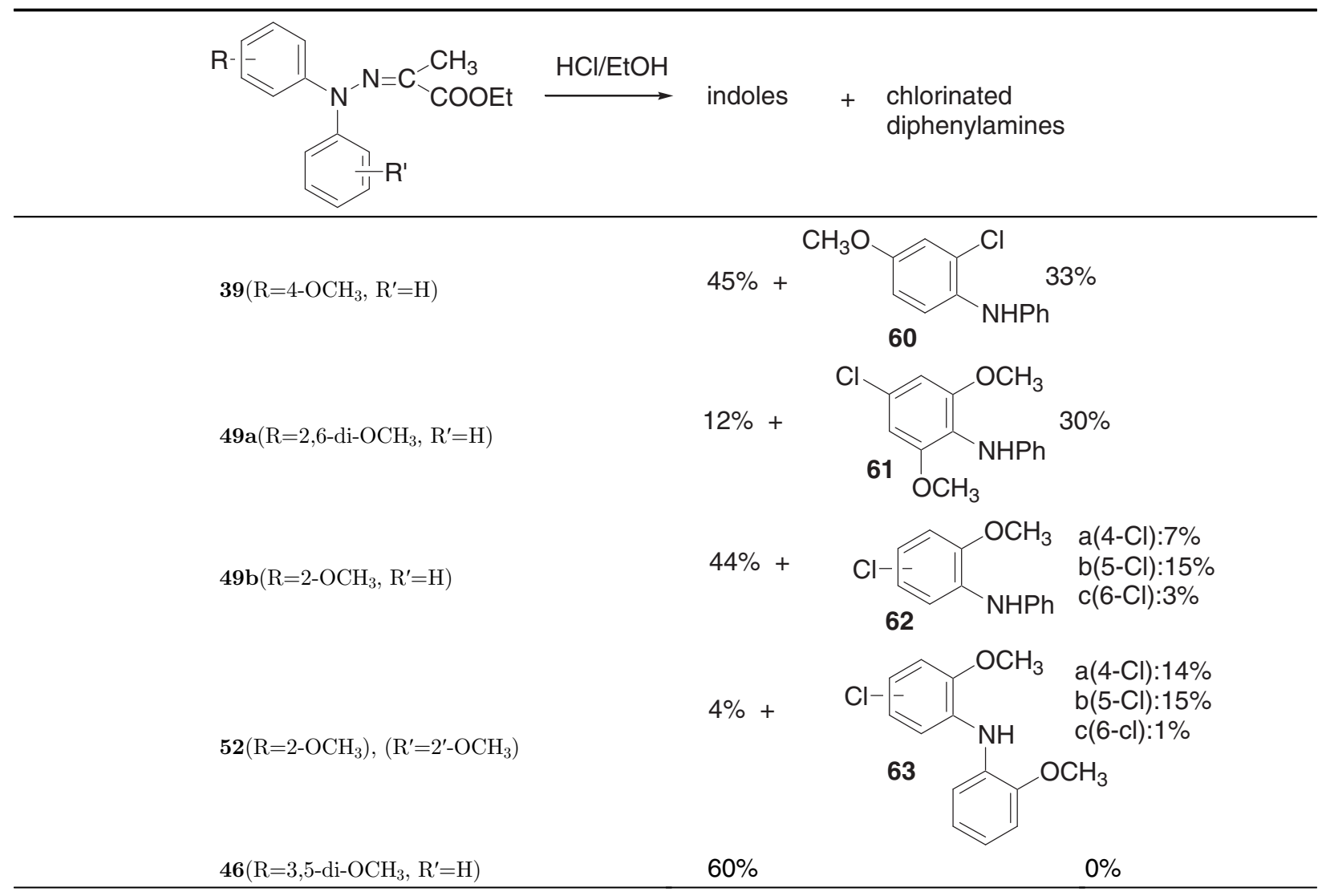

\section{Self-decomposition of methoxy- diphenylhydrazones}

As shown in Figs. 14, 15, and 16, F.I. of diphenylhydrazones carrying a methoxy group at the $o$ - or $p$-position $(\mathbf{3 9}, 49 \mathbf{a}, 49 \mathbf{b}, \mathbf{5 2})$ of the $N$ atom yielded comparatively poor yields of indole products. In fact, these reactions yielded a large amount of chlorinated diphenylamines other than indolic products, as shown in Table 3. ${ }^{22), 24)}$ These diphenylhy- 

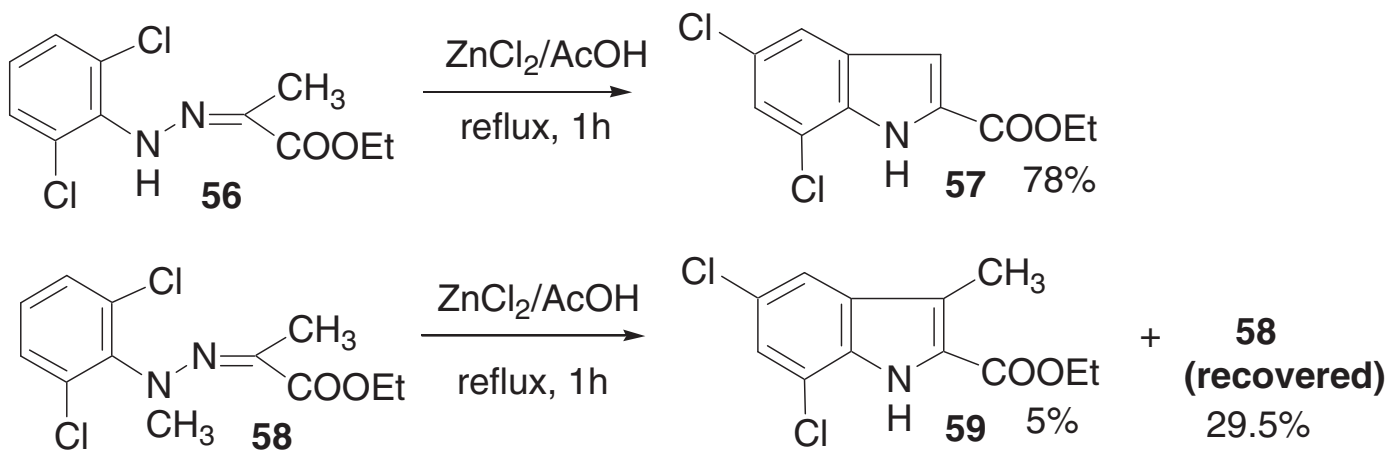

Fig. 17. F.I. of 2,6-dichlorophenylhydrazones.

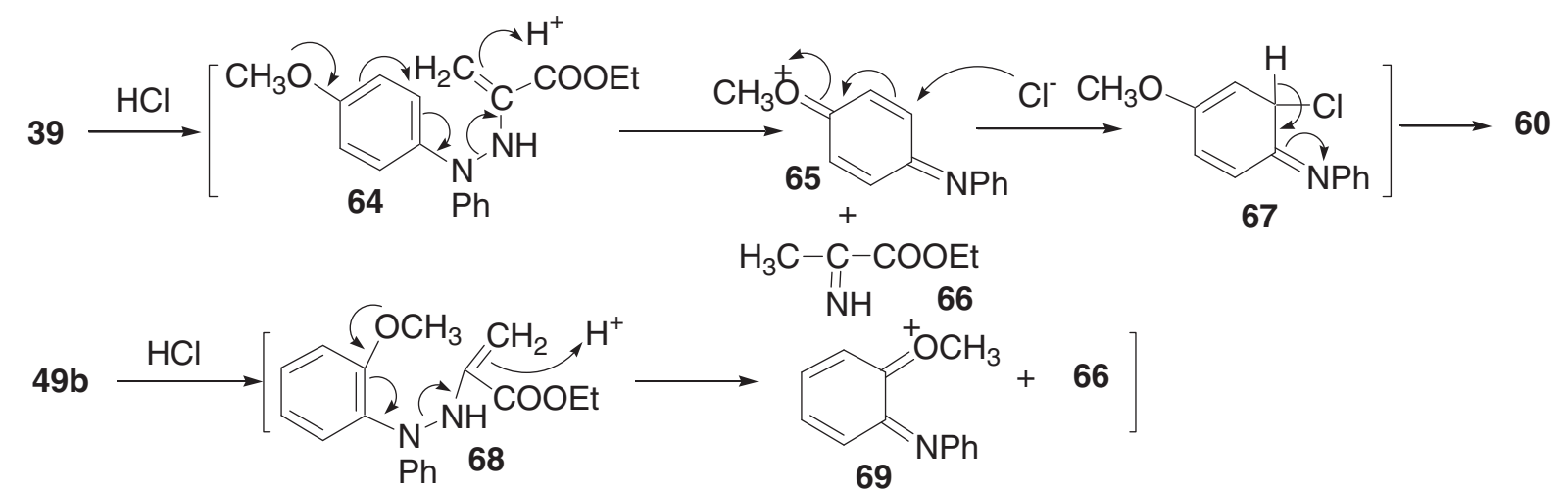

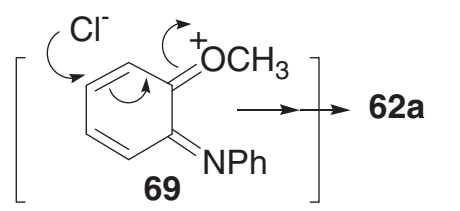

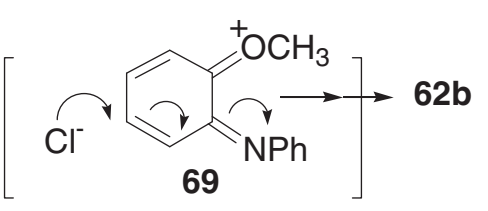

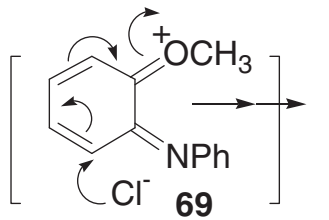

62c

Fig. 18. The mechanism of formation of chlorinated diphenylamines (60-62).

drazones, which have methoxy group(s) at the $o$ - or $p$-position from the $N$ atom, should have given the chlorinated diphenylamines by self-degradation before F.I. cyclization. The position of the introduced chlorine atom was the meta-position of the methoxy group. On the other hand, the diphenylhydrazones that had methoxy groups at the $m$-position of the $N$ atom (46) and had no methoxy group (43) did not yield such chlorinated diphenylamines.

Based on the facts described above, a mechanism for the abnormal formation of chlorinated diphenylamines was proposed as shown in Fig. 18. Because the formation mechanism of every chlorodiphenylamine was fundamentally the same, we can explain the mechanism in the reactions of diphenylhydrazones 39 and $49 \mathrm{~b}$ as shown in Fig. 18. As can be seen in the figure, the diphenylhydrazones were self- decomposed before proceeding to F.I. due to the resonance effect of the methoxy group.

The results described above led to another consideration. That is, we considered that the decomposition of the diphenylhydrazones would be possible with the general $\mathrm{NH}$-phenylhydrazone having a methoxy group, although such an example has not been reported yet. Sometimes, the F.I. of the methoxyphenylhydrazone may unexpectedly fail to give the corresponding indole in good yield, though the starting materials seem to disappear early in the reaction. Indeed, the total yield of the indoles of the F.I. of phenylhydrazones $\mathbf{5}$ and $\mathbf{1 2}$ did not exceed $45 \%$. This would have been the reason that a decomposition similar to that described in Fig. 18 occurred, even though the corresponding chlorinated aniline did not become trapped. 
Table 4. F.I. of 2-substituted phenylhydrazones

\begin{tabular}{|c|c|c|c|c|c|c|}
\hline & $\mathrm{N}_{\mathrm{H}}^{\mathrm{N}^{-}}{ }_{\mathrm{70}}^{\mathrm{N}}=\left\langle\mathrm{CO}^{\mathrm{CH}}\right.$ & $\mathrm{H}^{+}$ & $\mathrm{H}$ & $\begin{array}{c}+ \\
\text { Et }\end{array}$ & 72 & \\
\hline \multirow{2}{*}{$70(\mathrm{X}=)$} & \multirow{2}{*}{ Acid catalyst } & \multirow{2}{*}{ Temp./time } & \multicolumn{2}{|r|}{ Products } & \multicolumn{2}{|c|}{ Ratio } \\
\hline & & & 71 & 72 & $72(\mathrm{X}=\mathrm{H})$ & $71 /$ indoles \\
\hline $\mathrm{a}, \mathrm{X}=-\mathrm{NHAc}$ & $\mathrm{ZnCl}_{2} / \mathrm{AcOH}$ & Refl. $/ 1.5 \mathrm{~h}$ & $23 \%$ & $27 \%(\mathrm{X}=5-\mathrm{NHAc})$ & $0 \%$ & $46 \%$ \\
\hline \multirow[t]{2}{*}{$\mathrm{b}, \mathrm{X}=-\mathrm{SCH}_{3}$} & $\mathrm{HCl} / \mathrm{EtOH}$ & Refl. $/ 4.5 \mathrm{~h}$ & $26 \%$ & $3 \%\left(\mathrm{X}=3-\mathrm{SCH}_{3}\right)$ & $12 \%$ & $63 \%$ \\
\hline & $\mathrm{ZnCl}_{2} / \mathrm{AcOH}$ & Refl. $/ 5 \mathrm{~h}$ & $24 \%$ & $7 \%\left(\mathrm{X}=3-\mathrm{SCH}_{3}\right)$ & $11 \%$ & $57 \%$ \\
\hline$c, X=-P h$ & $\mathrm{ZnCl}_{2} / \mathrm{AcOH}$ & Refl./30 min & $61 \%$ & $21 \%(\mathrm{X}=4-\mathrm{Ph})$ & $0 \%$ & $74 \%$ \\
\hline $\mathrm{d}, \mathrm{X}=-\mathrm{CH}_{3}$ & $\mathrm{ZnCl}_{2} / \mathrm{AcOH}$ & $50^{\circ} \mathrm{C} / 3 \mathrm{~h}$ & $61 \%$ & $5 \%\left(\mathrm{X}=4-\mathrm{CH}_{3}\right)$ & $2 \%$ & $90 \%$ \\
\hline$e, \mathrm{X}=-\mathrm{Cl}$ & $\mathrm{ZnCl}_{2} / \mathrm{AcOH}$ & Refl. $/ 2 \mathrm{~h}$ & $64 \%$ & $15 \%(\mathrm{X}=5-\mathrm{Cl})$ & $0 \%$ & $81 \%$ \\
\hline $\mathrm{f}, \mathrm{X}=\mathrm{NO}_{2}$ & PPA & $120^{\circ} \mathrm{C} / 30 \mathrm{~min}$ & $78 \%$ & $0 \%$ & $0 \%$ & $100 \%$ \\
\hline $\mathrm{g}, \mathrm{X}=-\mathrm{CF}_{3}$ & $\mathrm{ZnCl}_{2} / \mathrm{AcOH}$ & Refl. $/ 1.5 \mathrm{~h}$ & $25 \%$ & $0 \%$ & $0 \%$ & $100 \%$ \\
\hline
\end{tabular}

Recently, a computational calculation was reported $^{26)}$ to explain the failure of F.I. to synthesize 3aminoindoles, during which attempt heterolytic N-N bond cleavage occurred without cyclization due to the substituent effect. This calculation method can be applied to our self-decomposition reaction shown in Table 3 for the mechanistic consideration.

\section{The F.I. of 2-substituted phenylhydrazones having substituents other than a methoxy group}

As described at the start of this article, in the F.I. of the 2-methoxyphenylhydrazone (5), the cyclization occurred on the methoxy side of the phenylhydrazone to give interesting indole derivatives. Thus, we were also interested in examining the F.I. of phenylhydrazones having other substituents at the 2-position. ${ }^{27)}$ The results of these examinations are shown in Table 4.

We obtained several results more unusual than those observed for F.I. of the 2-methoxyphenylhydrazone (5), namely: 1) the F.I. of these phenylhydrazones (70) with $\mathrm{HCl} / \mathrm{EtOH}$ generally proceeded with difficulty, except in the case of 2methylthiophenylhydrazone (70b); 2) no substitution in cyclization occurred in any case; 3) the abnormal indolic products were formed only by rearrangement of the 2-substituent of phenylhydrazone; 4) abnormal indolic products were formed only by rearrangement in phenylhydrazones having an ortho-para-orienting substituent, and the position of rearrangement differed according to the substituent; and 5) phenylhydrazones with a stronger electronattractive substituent (nitro or trifluoromethyl group) gave only a normal indolic product (as a result of the cyclization toward the vacant orthoposition).

\section{Synthesis of 7-oxygenated indoles by F.I.}

Based on all the above results, F.I. clearly does not realize the efficient synthesis of 7-methoxyindole. However, there is a high demand for the convenient synthesis of 7-oxygenated indole. To resolve this problem, we devised the following synthetic plan based on the results in Table 4. Considering that an abnormal indole product was not formed at all with phenylhydrazones having an $\mathrm{NO}_{2}$ or a $\mathrm{CF}_{3}$ group, the F.I. of the phenylhydrazone (73) having an electron-poor oxygen functional group was examined. For electron-poor oxygen functional groups, the tosyl-, mesyl-, and trifluoromesyl groups were chosen in order to convert these into a phenolic or alkoxy group easily later. $^{28)}$ The results are shown in Table 5.

PPA and $\mathrm{TsOH} /$ benzene were chosen as acid catalysts, since these are strong acids and also poor nucleophiles. The reactions proceeded under the conditions shown in Table 5 and generally gave two kinds of indolic products, namely the normally cyclized product, 7 -substituted indole (74), and the rearranged product, 5-substituted indole (75). As expected, however, considerably greater amounts of 7-substituted indoles were formed compared to 5substituted indoles. 
Table 5. 7-Oxygenated indoles by F.I.

\begin{tabular}{|c|c|c|c|c|c|c|c|}
\hline $\mathrm{RSO}_{2}$ & $\mathrm{~N}_{73}$ & $\frac{\mathrm{H}^{+}}{\mathrm{F} . \mathrm{I}}$ & $\mathrm{O} \quad \mathrm{H}_{74}$ & & & & C \\
\hline \multirow{2}{*}{ Run } & \multirow{2}{*}{$\begin{array}{c}73 \\
\mathrm{R}=\end{array}$} & \multirow{2}{*}{$\mathrm{H}^{+}$} & \multirow{2}{*}{$\begin{array}{l}\text { Conditions } \\
\text { Temp. time }\end{array}$} & \multicolumn{3}{|c|}{ Yield (\%) } & \multirow{2}{*}{$\begin{array}{l}\text { Rate }(\%) \\
\mathbf{7 0 / \text { total }} \\
\end{array}$} \\
\hline & & & & total & 74 & 75 & \\
\hline 1 & \multirow[t]{2}{*}{$-\mathrm{C}_{6} \mathrm{H}_{4}-\mathrm{CH}_{3}(\mathrm{p})(\mathrm{Ts})$} & PPA & $85^{\circ} \mathrm{C}, 30 \mathrm{~min}$ & 47 & 37 & 10 & 78.7 \\
\hline 2 & & TsOH/benzene & refl., $13.5 \mathrm{~h}$ & 72 & 54 & 18 & 75.0 \\
\hline 3 & \multirow[t]{2}{*}{$-\mathrm{CH}_{3}(\mathrm{Ms})$} & PPA & $50^{\circ} \mathrm{C}, 2 \mathrm{~h}$ & 46 & 39 & 7 & 84.8 \\
\hline 4 & & TsOH/benzene & refl., $3 \mathrm{~h}$ & 91 & 61 & 30 & 67.0 \\
\hline 5 & \multirow[t]{2}{*}{$-\mathrm{CF}_{3}(\mathrm{Tf})$} & PPA & $80^{\circ} \mathrm{C}, 1 \mathrm{~h}$ & 60 & 53 & 7 & 88.3 \\
\hline 6 & & TsOH/benzene & refl., $25 \mathrm{~h}$ & 82 & 73 & 9 & 89.0 \\
\hline
\end{tabular}

Table 6. Other type of 7-oxygenated indoles by F.I

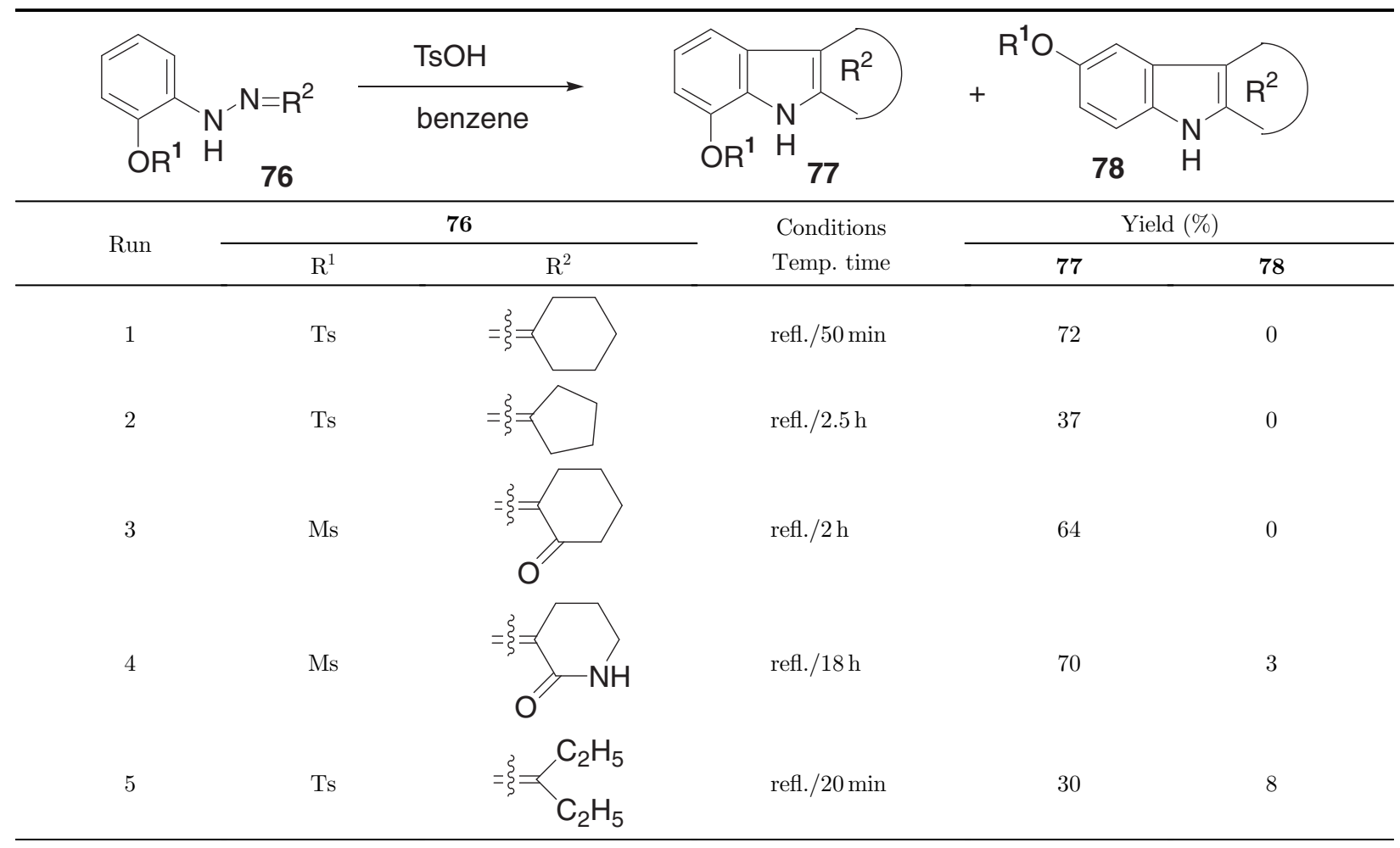

Next, the F.I. of other types of phenylhydrazone was examined as shown in Table 6. Although the overall yield varied, the formation ratio of the rearranged product (78) was low in every case, and thus it is certain that this method will practically give 7 -substituted indole (77) in reasonable yield. Heathcock and others ${ }^{29)}$ reported a method for preparing 7-oxygenated indole in which cyclization does not occur physically in the 2-substituent side in F.I. (Fig. 19). Though their method is an excellent one from the viewpoint of yield and positional specificity, the synthesis route is longer. When synthetic convenience is taken into consideration, our method may be better overall. 


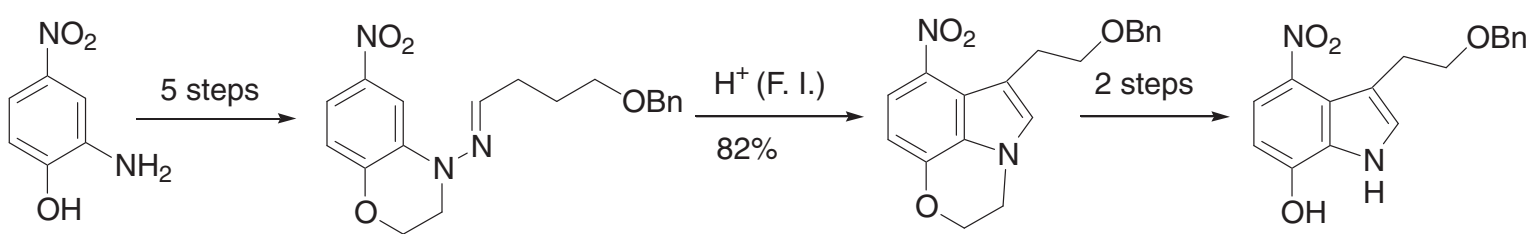

Fig. 19. Heathcock's result.<smiles>[B-]Oc1cc(Br)cc2cc(C(=O)OCC)[nH]c12</smiles>

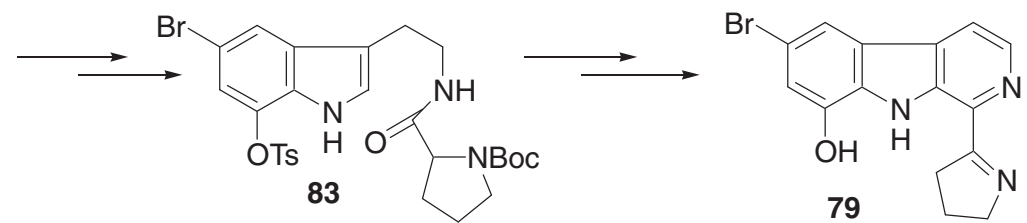

Fig. 20. The synthesis of Eudistomidin-A (79).

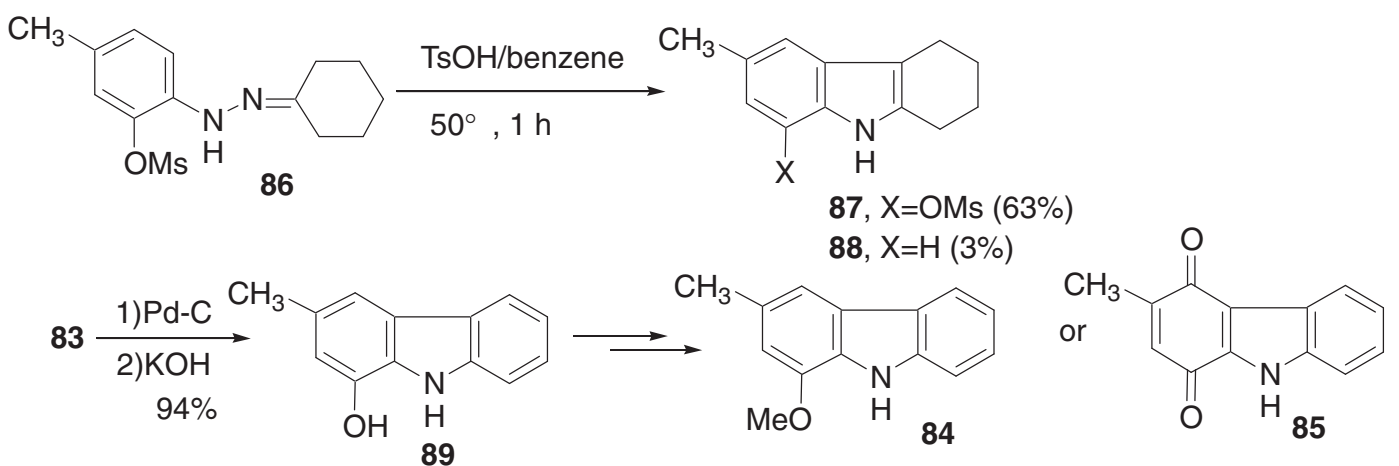

Fig. 21. The synthesis of Murrayafoline-A (84) and Murrayaquinone-A (85).

\section{Application of the synthetic method to the syntheses of naturally occurring 7-oxygenated indoles}

The above-mentioned synthetic method of 7 oxygenated indole via F.I. was applied to the syntheses of related natural products as follows: The first target was Eudistomidin- ${ }^{30)}(\mathbf{7 9})$, which was isolated from a type of sea sponge in Okinawa, Japan, and the outline ${ }^{28)}$ is shown in Fig. 20.

The F.I. of 2-tosyloxyphenylhydrazone (80) prepared from 5-bromo-2-aminophenol gave the expected indole $(\mathbf{8 1})$ as a sole product. After F.I. product (81) had been led to $\mathbf{8 2}$ with decarboxylation, the first synthesis of $\mathbf{7 9}$ was achieved via $\mathbf{8 3}$ based on the method of Hino et al. ${ }^{31)}$ The final detosylation was achieved by the hydrolysis with $\mathrm{KOH}$.
As the next application, Murrayafoline-A (84) and Murrayaquinone-A (85) isolated from a plant were synthesized $^{32)}$ (Fig. 21). The F.I. of the phenylhydrazone (86) prepared from 5-methyl-2-aminophenol gave the target indole $(\mathbf{8 7})$ in good yield with a minute amount of the abnormal product (88). The aromatization of $\mathbf{8 7}$, followed by hydrolysis, gave the phenolic compound (89). Methylation of $\mathbf{8 9}$ gave the natural product $(\mathbf{8 4})$, and oxidation of 89 with Fremy's salt gave the quinone natural product (85).

\section{Role of the enehydrazine part in the F.I. mechanism at the first cyclization step}

As described above, we established that the first cyclization step of the F.I. was promoted by substituting the electron-donating substituent on the benzene ring of phenylhydrazone (the opposite is also 
<smiles>[X]c1ccc(N[NH3+])cc1</smiles>
eq. 2
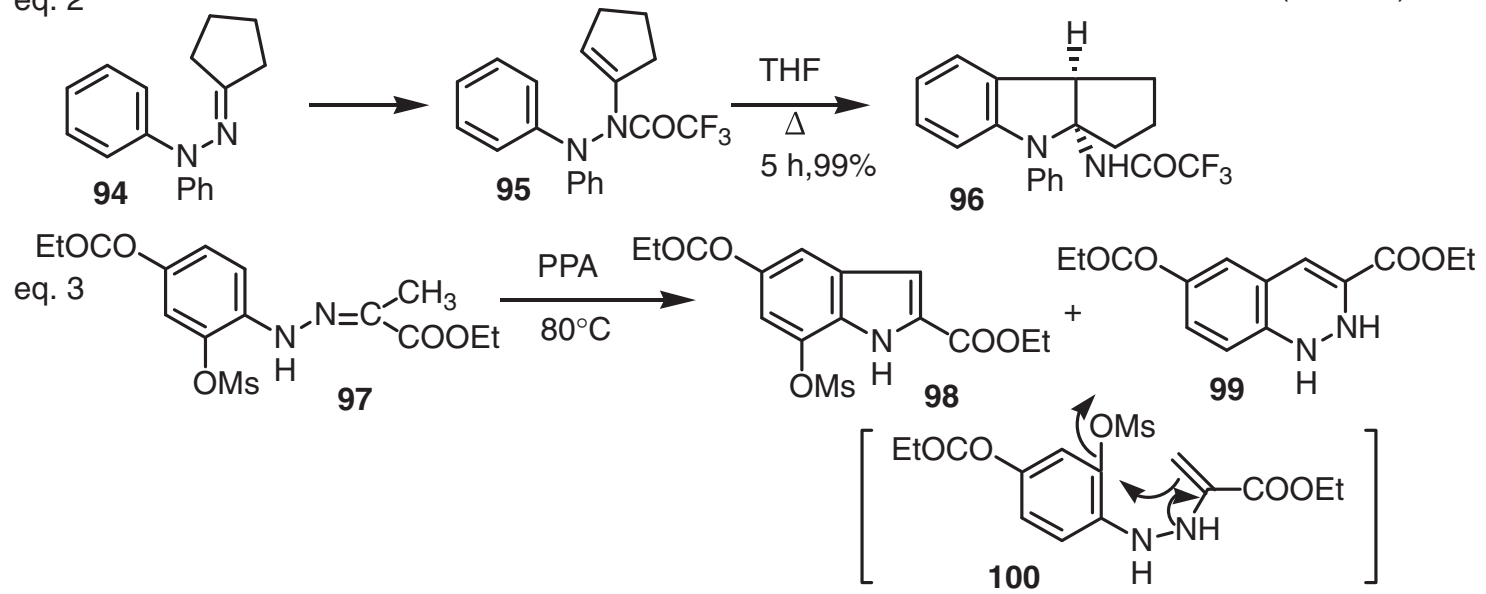

Fig. 22. The role of the enehydrazine part in F.I.

true). As a result, the movement of the electron is confirmed as to be $\mathbf{3 5}$ but not $\mathbf{3 5} \mathbf{5}^{\prime}$ in Fig. 12. On the other hand, the electronic effect in the enehydrazine part has been hardly understood until recently.

In the course of these experiments, ${ }^{33)}$ we noticed that the phenylhydrazone prepared from phenylhydrazine (90) and $\beta$-diketone (91) was actually in the enehydrazine structure (92) (Fig. 22). The enehydrazine part of $\mathbf{9 2}$ seems to have been rendered electron-poor by the carbonyl group. In these compounds, the F.I. of the phenylhydrazone (92, $\mathrm{X}=\mathrm{OMe}$ ) easily gave the corresponding indole product in $43 \%$ yield without an acid catalyst. Naito et al. ${ }^{34)}$ reported that the compound $(\mathbf{9 5})$ whose $\mathrm{N}$ atom of the enehydrazine part of the phenylhydrazone (94) was acylated easily was cyclized only by heating to give the corresponding indole $(\mathbf{9 6})$ (Fig. 22, eq. 2). They explained this result as follows: in this reaction the reactivity of the enehydrazine part was promoted by the enhancement of the LUMO character by the strong electro-attractivity of the trifluoroacetyl group, because in the [3,3]sigmatropy reaction exemplified by Claisen rearrangement, the reaction between two double bonds is wellknown to proceed by an appropriate combination of HOMO and LUMO. This reaction showed quite similar reactivity with ours (eq. 1). Naito et al. reported in their series of studies ${ }^{35)}$ that F.I. of $o$ substituted phenylhydrazone yielded an interesting compound corresponding to the intermediate $\mathbf{c}$ in Fig. 5. In these cases, the F.I. of the phenylhydrazone having a more electron-donative substituent at the ortho-position gave the higher yield of the compound which was formed by the cyclization to the substituted ortho-position, as described in Table 4.

On the other hand, we obtained the result that the F.I. proceeded more rapidly if the electronic density of the benzene part of phenylhydrazone increased by the substituent, as described earlier. Therefore, with respect to the first cyclization step of the F.I., it was verified that the electronic movement corresponded to that in $\mathbf{3 5}$, but not that in $\mathbf{3 5}^{\prime}$, in Fig. 12.

Moreover, we discovered that the [3,3]sigmatropic reaction might not take place when there is a leaving group in the electron-poor benzene ring of phenylhydrazone $(\mathbf{9 7}),{ }^{36)}$ as shown in eq. 3 in Fig. 22. In this case, the dihydrocinnoline derivative $(\mathbf{9 9})$ was formed in addition to the expected indole $(\mathbf{9 8})$. The cinnoline (99) was surely formed, based on the result that the enehydrazine part attacked the root of the $\mathrm{MsO}$ group in a nucleophilic manner, followed by an aromatic addition-elimination reaction but not cyclization, as shown by the intermediate $\mathbf{1 0 0}$. Therefore, this can be considered one of the experiments which prove that the movement of the electron in the first cyclization step in F.I. is shown by $\mathbf{3 5}$, but not by $\mathbf{3 5}$ '. 


\section{Consideration of F.I. on synthetic chemistry}

The experimental methodology of F.I. of the usual phenylhydrazone that has been carried out in acidic media by heating has been proven correct. Because it is a $[3,3]$ sigmatropy reaction, heating is necessary. Although the F.I. can progress even if the acid is not used, the reaction that uses the acid will give the greater result. It is thought that this is because the proton promotes the isomerization from phenylhydrazone to enehydrazine and improves the LUMO character in the part of enehydrazine that promotes the reaction. The electron-donative substituent on the phenylhydrazone makes the F.I. proceed easily, but F.I. of the phenylhydrazone having a methoxy group may cause an abnormal reaction to give the corresponding indole in poor yield.

Recently, a new method for the F.I. was reported $^{37)}$ using microwaves instead of a conventional heating procedure. The significant features of this method include its short reaction time and good ease of preparation. Accordingly, this method will be a useful alternative procedure.

\section{Acknowledgements}

This research started when the author was at the Chiba University. We wish to express our gratitude for the guidance of the late Professor Nisaburo Ikeda and also the late Professor Hisashi Ishii. Moreover, we wish to express our gratitude to the staff and students at the Faculty of Pharmaceutical Sciences at Chiba University and the School of Pharmaceutical Sciences at Toho University.

\section{References}

1) Manske, R.H., Brossi, A. and Cordell, G.A. (ed.) (1950-2010) The Alkaloids. Vols. 1-68. Academic Press Inc., Publishers, New York.

2) Ban, Y., Murakami, Y., Iwasawa, Y., Tsuchiya, M. and Takano, N. (1988) Indole alkaloids in medicine. Med. Res. Rev. 8, 231-308.

3) Reviews: a) Robinson, B. (1963) The Fischer indole synthesis. Chem. Rev. 63, 373-401; b) Robinson, B. (1969) Recent studies on the Fischer indole synthesis. Chem. Rev. 69, 227-250; c) Robinson, B. (1982) The Fischer Indole Synthesis. John Wiley and Sons, New York; d) Hughes, D.L. (1993) Progress in the Fischer indole reaction. A review. Org. Prep. Proced. Int. 25, 607-632.

4) a) The first total synthesis: Fukuyama, T. and Lihu, Y. (1977) Synthetic studies toward mitomycins.III. Total syntheses of Mitomycins A and C. Tetrahedron Lett., 4295-4298; b) (1989) Practical total synthesis of $( \pm)$ mitomycin C. J. Am. Chem. Soc. 111, 8303-8304.

5) Papalardo, G. and Vitali, T. (1958) Ricerche nella serie dell'indolo.- Nota III. Spettri U.V. di alcuni metossindoli, di alcuni acidi ed esteri metossindol2-carbossilici. Gazz. Chim. Ital. 88, 574-590. [Chem. Abst. 53, 20030a (1959)]

6) a) Ishii, H., Murakami, Y., Suzuki, Y. and Ikeda, N. (1970) The substitution and migration of methoxyl group in the Fischer indolization of ethyl pyruvate 2-methoxy phenylhydrazone. Tetrahedron Lett. 1181-1184; b) Ishii, H., Murakami, Y., Hosoya, K., Takeda, H., Suzuki, Y. and Ikeda, N. (1973) Fischer indolization and its related compounds. V. Indolization of ethyl pyruvate 2-methoxyphenylhydrazone and its N-methyl derivative with protic acids. Unpredictable products and the mechanism. Chem. Pharm. Bull. 21, 1481-1494.

7) Ishii, H., Murakami, Y., Furuse, T., Hosoya, K. and Ikeda, N. (1973) Fischer indolization and its Related compounds. VI. Effect of reagents and substituent of the ortho-substituted phenylhydrazone on abnormal Fischer indolization. Chem. Pharm. Bull. 21, 1495-1505.

8) Gannon, W.F., Benigni, J.D., Dickson, D.E. and Minnis, R.L. (1969) The Fischer indole cyclization of several ortho-substituted phenylhydrazones. J. Org. Chem. 34, 3002-3006.

9) a) Carlin, R.B. and Carlson, D.P. (1959) The Fischer indole synthesis. VI. A non-aromatic intermediate and a new class of hydroindoles. J. Am. Chem. Soc. 81, 4673-4682; b) Carlin, R.B., Magistro, A.J. and Mains, G.J. (1964) An $\mathrm{N}^{15}$ tracer study of the transformations of acetophenone 2,6-xylylhydrazone under the conditions of the Fischer indole synthesis. J. Am. Chem. Soc. 86, 5300-5301.

10) Goldsmith, E.A. and Lindwall, H.G. (1953) Studies in the benzindoles series. J. Org. Chem. 18, 507515.

11) Livingston, R. (1973) In Rodd's Chemistry of Carbon Compounds, Vol. IV, Part A, Heterocyclic Compounds (ed. Coffey, S.). 2nd ed. Elsevier, Amsterdam, pp. 482-486.

12) Ishii, H., Murakami, Y., Watanabe, T., Iwazaki, A., Suzuki, H., Masaka, T. and Mizuma, Y. (1984) Formation of an angular 5-chlorobenz[e]indole by the Fischer indolization of a 1-methoxy-2-naphthylhydrazone: correction of the structure of the so-called linear ethyl 9-methoxy- $1 H$-benz $[f]$ indole2 -carboxylate to the angular ethyl 5 -chloro- $3 \mathrm{H}$ benz $[e]$ indole-2-carboxylate. J. Chem. Research (S), 326-327; J. Chem. Research (M), 2947-2997.

13) Ishii, H., Murakami, Y., Watanabe, T., Suzuki, H., Yasuda, Z., Ikeda, N., Mitsui, H. and Tani, S. (1983) Fischer indolization and its related compounds. XVIII. Formation of four unexpected angular benz[e]indoles on Fischer indolization of ethyl phenylpyruvate 2-[(1,4-dimethoxy-2-naphthyl)hydrazone]. Chem. Pharm. Bull. 31, 43914400 .

14) Ishii, H., Murakami, Y., Watanabe, T., Suzuki, H. and Maejima, H. (1983) Fischer indolization and 
its related compounds. XIX. Syntheses of ethyl 4-methoxy- and ethyl 5-methoxy-1-phenyl-3Hbenz[e]indole-2-carboxylate. Chem. Pharm. Bull. 31, 4401-4408.

15) Hemetzberger, H., Knittel, D. and Weidmann, H. (1969) Syntheses von $\alpha$-Azidozimtsäureestern. Monatsh. Chem. 100, 1599-1603.

16) Ishii, H., Murakami, Y., Furuse, T., Hosoya, K., Takeda, H. and Ikeda, N. (1973) Fischer indolization and its related compounds-VII. Development of abnormal Fischer indolization of ortho-methoxyphenylhydrazone to provide a synthetic method for useful indole derivatives possessing an active methine group at $\mathrm{C}_{6}$ and novel 3,6'-biindole derivatives. Tetrahedron 29, 1991-2003.

17) Miyaura, N. and Suzuki, A. (1995) Palladiumcatalyzed cross-coupling reactions of organoboron compounds. Chem. Rev. 95, 2457-2483.

18) Nwaji, M.N., Onyiriuka, S.O. and Taylor, D.A.H. (1972) 6-(3-Methylbuta-1,3-dienyl)indole from Monodora tenuifolia. J. Chem. Soc. Commun., 327.

19) Benešová, V., Samek, Z., Herout, V. and Šorm, F. (1969) Plant substances. XXIX. Isolation and structure of two new indole alkaloids. Collect. Czech. Chem. Commun. 34, 1807-1809.

20) Ishii, H., Murakami, Y., Furuse, T., Takeda, H. and Ikeda, N. (1973) Synthesis of the naturally occurring 6-(3-methylbuta-1,3-dienyl)indole via advanced Fischer indolization of a 2-methoxyphenylhydrazone derivative. Tetrahedron Lett., 355-358.

21) a) Ruchardt, C., Eichler, S. and Kratz, O. (1965) Eine neue Reaktion von Pyridin-N-oxyd mit Saureanhydriden oxidation utilizing pyridine Noxide. Tetrahedron Lett., 233-236; b) Chohen, T. Song, I.W. and Fager, J.H. (1965) A route to aldehydes and ketones by a four-electron decarboxylation. Tetrahedron Lett., 237-241.

22) Ishii, H., Takeda, H., Hagiwara, T., Sakamoto, M., Kogusuri, K. and Murakami, Y. (1989) Fischer indolization and its related compounds. Part 21. Direction on the cyclisation in the Fischer indolisation of ethyl pyruvate 2 - $(p$ - or $m$-substituted phenyl)phenylhydrazones. J. Chem. Soc., Perkin Trans. 1, 2407-2414.

23) Robinson, B. (1982) In The Fischer Indole Synthesis. John Wiley and Sons, New York, p. 172.

24) a) Ishii, H., Sugiura, T., Akiyama, T., Watanabe, T. and Murakami, Y. (1990) Fischer indolization and its related compounds. XXIII. Fischer indolization of ethyl pyruvate 2-(2,6-dimethoxyphenyl)phenylhydrazone. Chem. Pharm. Bull. 38, 2118-2126; b) Ishii, H., Sugiura, T., Kogusuri, K., Watanabe, T. and Murakami, Y. (1991) Fischer indolization and its related compounds. XXIV. Fischer indolization of ethyl pyruvate 2-(2-methoxyphenyl)phenylhydrazone. Chem. Pharm. Bull. 39, 572-578; c) Murakami, Y., Watanabe, T., Hagiwara, T., Akiyama, Y. and Ishii, H. (1995) Fischer indolization of ethyl pyruvate 2-[2-(trifluoromethyl)phenyllphenylhydrazone and new insight into the mechanism of the Goldberg reaction. (Fischer indolization and its related compounds. XXVI.). Chem. Pharm. Bull. 43, 1281-1286.

25) Ishii, H., Murakami, Y. and Ishikawa, T. (1990) Fischer indolization and its related compounds. XXII. Fischer indolization of ethyl pyruvate 2-(2chloro- and 2,6-dichlorophenyl)methylhydrazones. Chem. Pharm. Bull. 38, 597-604.

26) Çelebi-Ölçüm, N., Boal, B.W., Huters, A.D., Garg, N.K. and Houk, K.N. (2011) Why do some Fischer indolizations fail? J. Am. Chem. Soc. 133, 57525755 .

27) Murakami, Y., Watanabe, T., Yokoyama, Y., Naomachi, J., Iwase, H., Watanabe, N., Morihata, M., Okuyama, N., Kamakura, H., Takahashi, T., Atoda, H., Tojo, T., Morita, K. and Ishii, H. (1993) Fischer indolization and its related compounds. XXV. Fischer indolization of variously ortho-substituted phenylhydrazones. Chem. Pharm. Bull. 41, 1910-1919.

28) a) Murakami, Y., Takahashi, H., Nakazawa, Y., Koshimizu, M., Watanabe, T. and Yokoyama, Y. (1989) The improved synthesis of 7-oxygenated indoles by Fischer indolization and its application to the first total synthesis of eudistomidin-A. Tetrahedron Lett. 30, 2099-2100; b) Murakami, Y., Watanabe, T., Takahashi, H., Yokoo, H., Nakazawa, Y., Koshimizu, M., Adachi, N., Kurita, M., Yoshino, T., Inagaki, T., Ohishi, M., Watanabe, M., Tani, M. and Yokoyama, Y. (1998) Fischer indolization of 2-sulfonyloxyphenylhydrazones: a new and practical approach for preparing 7-oxygenated indoles and application to the first synthesis of eudistomidin-A. (Fischer indolization and its related compounds. Part 28). Tetrahedron $\mathbf{5 4}, 45-64$.

29) Szczepankiewicz, B.G. and Heathcock, C.H. (1997) A novel method for suppression of the abnormal Fischer indole synthesis. Tetrahedron 53, 88538870 .

30) Kobayashi, J., Nakamura, H., Ohizumi, Y. and Hirata, Y. (1986) Eudistomidin-A, a novel calmodulin antagonist from the okinawan tunicate eudistoma glaucus. Tetrahedron Lett. 27, 11911194.

31) Hino, T., Lai, Z., Seki, H., Hara, R., Kuramochi, T. and Nakagawa, M. (1989) 1-(1-Pyrrolin-2-yl)- $\beta$ carbolines. Synthesis of Eudistomins H, I, and P. Chem. Pharm. Bull. 37, 2596-2600.

32) Murakami, Y., Yokoo, H. and Watanabe, T. (1998) New syntheses of murrayafoline-A and murrayaquinone-A via Fischer indolization of 2-sulfonyloxyphenylhydrazone. (Fischer indolization and its related compounds. Part 29). Heterocycles 49, $127-132$.

33) Suzuki, H., Tsukakoshi, Y., Tachikawa, T., Miura, Y., Adachi, M. and Murakami, Y. (2005) A new synthesis of 4 -oxygenated $\beta$-carboline derivatives by Fischer indolization. Tetrahedron Lett. 46, $3831-3834$.

34) a) Miyata, O., Muroya, K., Hiramatsu, H. and Naito, T. (1999) Thermal cyclization of N-trifluoroacetyl enehydrazines under milder conditions: A novel 
entry into the Fischer indole synthesis. Tetrahedron Lett. 40, 3601-3604; b) Miyata, O., Takeda, N. and Naito, T. (2006) Highly efficient synthesis of heterocyclic compounds based on reactivity of trifluoroacetyl group. J. Synth. Org. Chem. Jpn. 64, 1282-1293.

35) Miyata, O., Kimura, Y. and Naito, T. (1999) Unambiguous characterization of dienylimines as intermediates in Fischer indolisation of o-substituted N-trifluoroacetyl enehydrazines. Chem. Commun., 2429-2430.

36) Murakami, Y., Yokoo, H., Yokoyama, Y. and Watanabe, T. (1999) Substituent effects in the Fischer indoization of (2-sulfonyloxyphenyl)hydra- zones. (Fischer indolization and its related compounds. XXX). Chem. Pharm. Bull. 47, 791-797.

37) Recent papers: a) Desroses, M., Wieckowski, K., Stevens, M. and Odell, L.R. (2011) A microwaveassisted, propylphosphonic anhydride $\left(\mathrm{T}^{3} \mathrm{P}^{\circledR}\right)$ mediated one-pot Fischer indole synthesis. Tetrahedron Lett. 52, 4417-4420; b) Creencia, E.C., Tsukamoto, M. and Horaguchi, T. (2011) Onepot-one-step, microwave-assisted Fischer indole synthesis. J. Heterocycl. Chem. 46, 1095-1102.

(Received Aug. 31, 2011; accepted Nov. 22, 2011)

\section{Profile}

Yasuoki Murakami was born in 1937 in Hiroshima Prefecture. He graduated from the Faculty of Pharmaceutical Sciences, the Chiba University in 1961 and was then educated at the graduate school (Faculty of Pharmaceutical Sciences) in the University of Tokyo (Ph.D., 1968 on the stereochemical studies) under the direction of the late professor Shun-ichi Yamada. Then he worked as an assistant professor and a lecturer at the Faculty of Pharmaceutical Sciences, the Chiba University (1968-1978). During that time, he studied at the Department of Chemistry (Prof. James P. Kutney), the University of British Columbia, Canada, as a post-doctoral fellow, in a field of alkaloid synthesis (1974-1976). In 1978 he moved to the Faculty of Pharmaceutical Sciences, Toho University, Chiba, as a professor until his retirement (2003). During that time he

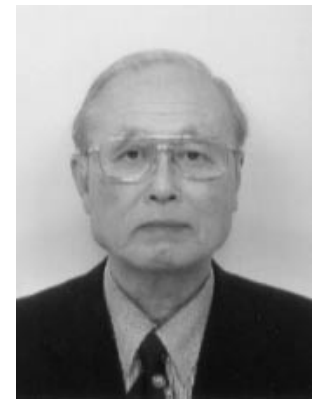
was a dean (1994-1998). After that, he became a professor of the Faculty of Pharmacy, Chiba Institute of Science, Chiba (2004-present). His research interests were the synthetic organic chemistry on indole, which is included in tryptophan and a lot of alkaloids and medicines, and the chemistry on ortho-substituted diacylanilines. On the basis of these studies, he received "Senji Miyata Foundation Award 1997" and "The Pharmaceutical Society of Japan Award for Divisional Scientific Contributions 2002". 